\title{
EL MONASTERIO DE MADRE DE DIOS. HISTORIA Y PATRIMONIO ARTÍSTICO DE LAS DOMINICAS SANLUQUEÑAS
}

\section{FERNANDO CRUZ ISIDORO}

Sanlúcar de Barrameda, Monasterio de la Anunciación del Señor, 2018, 679 páginas ISBN: 978-84-09-05032-1

La meritoria labor de investigación que sobre la ciudad de Sanlúcar de Barrameda ha realizado el profesor de la Universidad de Sevilla Fernando Cruz Isidoro se inició hace años, lo que le llevó a organizar, inventariar y catalogar los fondos documentales de varias instituciones sanluqueñas, favoreciendo el conocimiento de su riquísimo patrimonio con la publicación de varias monografías y un número ingente de artículos donde se recogen diferentes aspectos patrimoniales de la ciudad. El proceso iniciado culmina ahora con este trabajo sobre el monasterio de la Anunciación del Señor, vulgo de Madre de Dios, convento dominico con más de cinco siglos de vida y un patrimonio artístico de gran valor por su variedad y calidad. La monografía es fruto de una laboriosa investigación donde el trabajo de archivo ha sido fundamental, así como el análisis de las fuentes bibliográficas y el estudio y la catalogación de su patrimonio.

El trabajo está estructurado en dos grandes bloques, correspondiendo los cuatro primeros capítulos al patronato e historia del monasterio. En el primer capítulo recoge la fundación y patronazgo de los duques de Median Sidonia, desde la creación de un beaterio de monjas procedentes de Sevilla en 1479-1480, hasta su consolidación como monasterio con la Carta de Privilegio ducal en 1506, cuando a la institución se la dota con una importante aportación económica que se continuará a lo largo de todo el siglo XVI. Un nuevo impulso se produjo bajo la protección de la condesa de Niebla, doña Leonor Manrique de Sotomayor y Zúñiga, quien costeó la construcción de una nueva iglesia y un palacio en las dependencias de la clausura para su reclusión como beata terciaria. Su hijo, V duque de Medina Sidonia, ratificará el patronato en 1517 y, en los primeros años del siglo XVII, ampliará la capilla mayor como espacio funerario.

El segundo capítulo, que el propio autor califica de complejo, recoge la transformación y engrandecimiento del monasterio a lo largo del siglo XVIII. Esto fue posible a los legados de varias profesas de la adinerada familia Vint y Lila quienes aportaron copiosas rentas y propiedades que propiciaron la transformación arquitectónica del conjunto 
monacal y el enriquecimiento de su patrimonio artístico. Los dos últimos capítulos de este primer bloque están dedicados a la evolución del convento y su comunidad a lo largo de los siglos XIX, XX, hasta la actualidad. Período complicado con las sucesivas desamortizaciones y conflictos bélicos, que si bien no afectaron al inmueble, determinaron años muy difíciles.

El segundo bloque, dividido en tres capítulos, el autor desgrana todo el proceso y análisis constructivo, así como su rico patrimonio artístico. En el capítulo quinto se aborda el estudio de la construcción de la iglesia, sacristía y coros, desde sus inicios hasta nuestros días, con el análisis formal de su planta, alzados, cubiertas y decoración. Entre las primeras intervenciones cabe destacar la obra del ingeniero militar italiano Juan Pedro Livadote, entre 1574 y 1576, a quien se deben las trazas y la ampliación en 1605 de la nueva capilla mayor, que el autor atribuye al arquitecto y tratadista Alonso de Vandelvira, mientras que la decoración de yeserías es obra de Francisco de la Gándara Hermosa de Acevedo. Importantes fueron también las intervenciones que se realizaron en 1743 y 1752, en las que participaron los maestros Juan Rodríguez Portillo y su hijo Lázaro y por último la participación del arquitecto Torcuato José Benjumeda, autor de las dos portadas neoclásicas, realizadas en 1815.

El siguiente capítulo lo dedica al patrimonio artístico que se encuentra en las dependencias anteriormente citadas. Recoge cronológicamente las diferentes obras de arte que atesora el convento, destacando su procedencia, autores y catalogación con atribuciones muy acertadas sobre algunas obras. En el último capítulo se estudia el resto de la clausura y su patrimonio artístico, desconocido para el público en general y que, gracias al importante aparato gráfico con que se ilustra la monografía, permiten conocer el tesoro oculto de una de las clausuras más ricas de la provincia de Cádiz.

La investigación del profesor Cruz, exhaustiva y de fácil lectura, se debe al interés, tesón y esfuerzo de la comunidad dominica que conscientes de la riqueza histórica y patrimonial de su comunidad animaron al autor a realizarla y han posibilitado y sufragado la edición de la misma. Sea, por tanto, bienvenida esta monografía que completa el estudio de las comunidades de clausura femeninas de Sanlúcar de Barrameda.

Mar Mercedes Fernández Martín

Universidad de Sevilla 